effect on isolated guinea pig ileum, it is advisable to use Tyrode solution as a medium for the incubations.

We thank Dr. J. van Noordwijk for advice. The synthetic bradykinin was kindly supplied by Dr. R. Berde, Sandoz A. G., Basle.

\section{P. N. AARSEN} A. KEMP

Department of Pharmacotherapeutics, University of Amsterdam.

'Aarsen, P. N., and Kemp, A., Brit. J. Pharmacol., 19, 442 (1962). Edery, H., and Lewis, G. P., Brit. J. Pharmacol., 19, 299 (1962).

\section{Rapid Estimation of Amino-acids}

DurING an investigation of the physiology of the pitcher of Nepenthes, methods suitable for a field laboratory were required for estimating amino-acids produced during 'digestion' and for estimating the uptake of amino-acids by the pitcher. The ninhydrin reaction in its usual form was too slow (Milton and Waters ${ }^{1}$ specify $100^{\circ} \mathrm{C}$ for $\mathrm{l} \mathrm{h}$ ) and the only colorimeter available was unsuited to field use.

The possibility of measuring the rate of the reaction, instead of the total amount of pigment formed, was therefore investigated.

A test-tube containing a solution of known amounts of ninhydrin and glycine in phosphate buffer was placed in a boiling water bath and the time taken for the appearance of a perceptible colour measured. This time was linearly related to the reciprocal of the product of the concentration of ninhydrin and the concentration of aminoacid (Fig. 1). This relation has been found to be valid over an eight-fold range of amino-acid and ninhydrin concentration. The rate of reaction was eritically dependent on the degree of agitation of the sample. Consistent results were obtained only when the test-tube rested on the bottom of the water bath; presumably this caused reproducible convection currents in the reaction mixture.

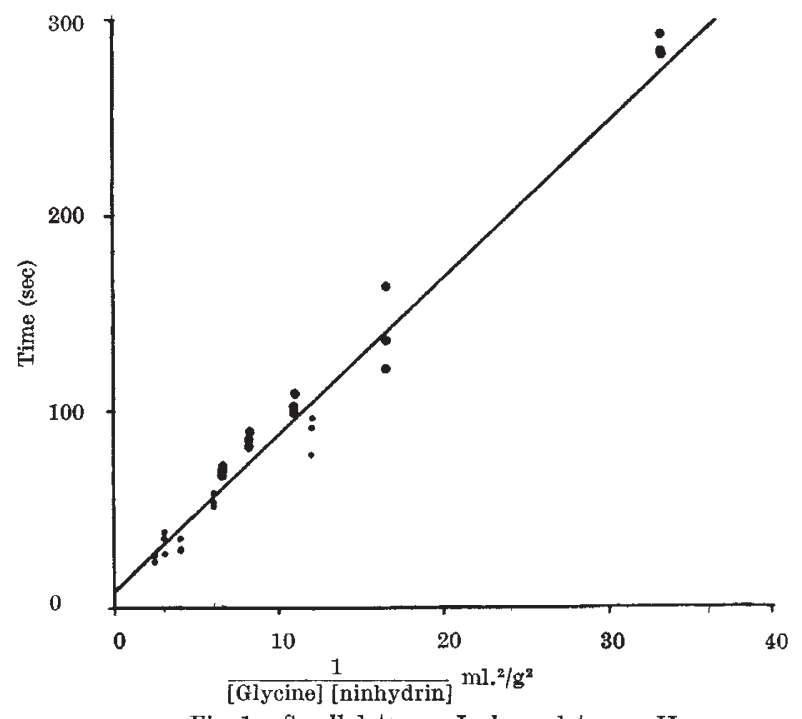

Fig. 1. Small dots, run I; large dots, run II

Usually $1 \mathrm{ml}$. of an unknown glycine solution (about $0.05-0.25 \mathrm{mg} / \mathrm{ml}$.) was added to $1 \mathrm{ml}$. of a standard solution of ninhydrin $(2 \mathrm{mg} / \mathrm{ml}$.) in a $p H 7.0 \mathrm{M} / 15$ phosphate buffer in a 5/8-in. test-tube. When the colour appeared too slowly or too quickly for convenience, the test was repeated with a stronger or weaker ninhydrin solution as appropriate. The initial colour change was more reliably detected when a blank tube, containing buffer or water only, was included.

Although the reaction described is of limited application, the measurement of the rate of reaction instead of total reaction may be useful when speed is more important than precision.

Rothamsted Experimental Station,

B. ORChard Harpenden, Herts.

${ }^{1}$ Milton, R. F., and Waters, W. A., Methods of Quantitative Microanalysis (Edward Arnold and Co., London, 1949).

\section{Neutral Glycolipids of Human Blood Serum, Spleen and Liver}

THE glycolipids of organs outside the central nervous system have been subject to sporadic investigations only. For many years it has been well known that in Gaucher's disease there is a strong accumulation of cerebrosides in spleen. These are glucocerebrosides and not galactocerebrosides, the normal constituents of normal brain ${ }^{1}$. More complex glycosphingosides-ceramide-dihexosides and aminoglycolipids-have been isolated from spleen and red blood cells ${ }^{2-7}$. With modern chromatographic methods an investigation of the whole glycolipid profile of red blood cell stroma and spleen in different mammals is carried out by Yamakawa and collaborators 8,9 . Independently of the Japanese group we are investigating the glycosphingolipid profile of human blood serum liver and spleen.

Serum is poured into $5 \mathrm{vol}$. of ethanol, the extract is evaporated and the lipids re-extracted with chloroform/ methanol $2: 1, \mathrm{v} / \mathrm{v}$. The lipids of lyophilized or acetonedried spleen or liver are extracted by boiling chloroform/ methanol 2:1, v/v. The lipid extracts of serum, liver and spleen are evaporated, hydrolysed with $0.5 \mathrm{M}$ potassium hydroxide in water at $35^{\circ} \mathrm{C} 16 \mathrm{~h}$ and acidified to $p \mathrm{H} \mathrm{4-5.}$ The lipids are extracted with chloroform-methanol and the glycolipids separated by chromatography on silicic acid with chloroform-methanol mixtures ${ }^{10}$. The total glycolipids are separated into neutral and acid fractions by chromatography on diethylaminoethyl (DEAE) cellulose ${ }^{11}$. The neutral glycolipids are then fractionated on columns of magnesium silicate ('Florisil') or silicic acid, or on thin-layer plates of silica-gel $G$ (ref. 12).

Four neutral glycolipid fractions (Table 1) have been isolated from each source. All consisted of a ceramide linked to a carbohydrate moiety. They have been tentatively identified as ceramide- monohexosides (cerebrosides), -dihexosides, -trihexosides and -trihexoside- $N$ acetylhexosamine. The investigation reported here has confirmed that normal human serum, liver and spleen" cerebrosides contain glucose instead of galactose. In the ceramide-dihexosides the carbohydrate moiety is lactose. Under release of galactose only the trihexosides could be converted by mild acid hydrolysis to mono- and dihexosides with the same $R_{F}$-values as of the normally occurring ones. The linkage of the second galactose to the lactose unit is still unknown.

Makita and Yamakawa ${ }^{9}$ and Rapport, Skipski and Sweeley ${ }^{18}$ have only been able to find saturated fatty acids in their spleon glycolipids, but Radin and Akahorit reported the presence of nervonic acid in Gaucher cerebrosides. Fig. 1 shows two spots of mono-, di- and trihexosides in our samples. The faster moving spot contains the hexosides with normal fatty acids, and the slower

Tade 1. Relative Distribution, Composition and $R_{F}$ Valdes of NedTral GLYCOLIPIDS OF HUMAN BLOOD SERUM, LIVER aND SPLEeN

\begin{tabular}{|c|c|c|c|c|c|c|}
\hline \multirow[b]{2}{*}{ Glycolipid } & \multicolumn{3}{|c|}{ Relative distribution } & \multicolumn{2}{|c|}{ Molar ratio } & \\
\hline & & per cent & & Nitrogen & Sugars & \\
\hline Cera & oerwm & Liver & Spleen & Hexuse & & \\
\hline monol & $40-50$ & $15-20$ & $10-15$ & $1: 1$ & Glucose 1 & $0 \cdot 67$ \\
\hline $\begin{array}{l}\text { Ceramide- } \\
\text { dihexoside }\end{array}$ & $45-55$ & $65-75$ & $50-60$ & $1: 2$ & $\begin{array}{l}\text { Glucose } 1 \\
\text { Galactose 1 }\end{array}$ & $\begin{array}{l}0.39 \\
0.35\end{array}$ \\
\hline $\begin{array}{l}\text { Ceramide- } \\
\text { trihexoside }\end{array}$ & $5-10$ & $7-10$ & $12-18$ & $1: 3$ & Glucose 1 & $\begin{array}{l}0 \cdot 25 \\
0.22\end{array}$ \\
\hline $\begin{array}{l}\text { Aminoglyco- } \\
\text { lipid }\end{array}$ & $2-5$ & $8-12$ & $12-18$ & $2: 3$ & $\begin{array}{l}\text { Glucose 1 } \\
\text { Galactose } 2 \\
\text { Galactosamine } 1\end{array}$ & $0 \cdot 14$ \\
\hline
\end{tabular}

